\title{
Eficacia antibacteriana de tres selladores endodónticos frente al Enterococcus faecalis
}

\author{
Antibacterial effectiveness of three endodontic sealers against Enterococcus faecalis.
}

\author{
David Heredia- Veloz ${ }^{1, a}$, Dunia Abad-Coronel 1,b,d, Ebingen Villavicencio- Caparó ${ }^{1, c}$.
}

\section{RESUMEN}

Objetivos: Este estudio tiene como objetivo la comparación de la eficacia antibacteriana sobre el Enterococcus faecalis, de tres cementos selladores de obturación utilizados en la terapia endodóntica, determinada mediante la medición del tamaño del halo inhibitorio. Material y métodos: se realizó un estudio comparativo in vitro, en el cual se utilizó el método de difusión en el agar de Müller- Hinton. Se calculó una muestra de 10 replicaciones por cemento haciendo un total de 30 unidades de estudio (mediante el programa $\mathrm{G}$ Power 3.1). Los datos del halo inhibitorio fueron medidos en milímetros después de 24 horas de incubación, a una temperatura de $37^{\circ} \mathrm{C}$, los resultados obtenidos se anotaron en una ficha elaborada por el autor, para posteriormente procesarlos mediante el análisis estadístico de Shapiro-Wilk, Kruskal-Wallis y U de Mann Whitney. Resultados: El sellador a base de resina epóxica (TOPSEAL) presentó un halo de inhibición de $7,7 \mathrm{~mm}$, el sellador a base de hidróxido de calcio (SEALAPEX) provocó un halo inhibitorio de $6,0 \mathrm{~mm}$ y el sellador a base de óxido de zinc y eugenol (GROSSFAR) presentó un halo de inhibición de $8,4 \mathrm{~mm}$, siendo el de mayor eficacia de los tres selladores utilizados en este estudio. Conclusiones: Con este estudio se llegó a la conclusión que los selladores estudiados no son iguales entre si con respecto a su eficacia antibacteriana contra el Enterococcus faecalis.

PALABRAS CLAVE: Enterococcus faecalis, selladores endodónticos, eficacia antibacteriana, halo inhibitorio. 


\section{SUMMARY}

Objectives: The aim of this study was the comparison of antibacterial effectiveness of three endodontic sealers, used in endodontic therapy. The antibacterial effectiveness of sealers was determinate by measuring the inhibitory halo against Enterococcus faecalis. Material and methods: A comparative in vitro study was done; the method of agar diffusion of Müller- Hinton was used. A sample of 10 replications for each sealer was estimated with the help the program (G Power 3.1) the total of sample was the 30 units of study. The data of inhibitory halo was measured in millimeters after 24 hours, incubated a temperature of $37^{\circ} \mathrm{C}$, the results was registered in a format developed by the author, later the results were processed by statistical analysis Shapiro-Wilk, Kruskal-Wallis and U de Mann Whitney. Results: The resin- based sealer (TOPSEAL) showed an inhibitory halo of $7.7 \mathrm{~mm}$; the hydroxide of calcium - based sealer (SEALAPEX) was of $6.0 \mathrm{~mm}$ whereas the oxide of zinc and eugenol - based sealer showed an inhibitory halo of $8.4 \mathrm{~mm}$, this inhibitory halo was the biggest in this study. Conclusions: This study concluded that the sealers used in this study are not equal in their antibacterial effectiveness against Enterococcus faecalis.

\section{KEYWORDS: Enterococcus faecalis, endodontic sealer, antibacterial effectiveness, inhibitory halo.}

\section{INTRODUCCIÓN}

El objetivo fundamental de la terapia endodóntica es la eliminación de microorganismos del sistema de conductos radiculares, mediante la preparación química, mecánica y la posterior obturación para evitar su reinfección, siendo indispensable un sellado tridimensional del sistema de conductos(1,2).

La preparación química y mecánica consigue una gran reducción de la población bacteriana, aunque numerosos estudios demuestran la resistencia y persistencia de especies bacterianas Gram positivas y negativas a esta preparación; una de las especies que juega un papel muy importante en la etiología de las lesiones periapicales persistentes y fracasos endodónticos es el Enterococcus faecalis (E. faecalis), debido a que este microorganismo posee resistencia a los procedimientos biomecánicos y a la medicación intraconducto (2-4). Por las razones mencionadas se recomienda el uso de un sellador endodóntico con capacidad antibacteriana $(3,5)$, que evite el desarrollo de una infección residual persistente, impidiendo que las bacterias de la cavidad oral ingresen en el sistema de conductos nuevamente, alcancen los tejidos periapicales y provoquen daños en estos; de la misma manera se evite el ingreso de exudados desde los tejidos periapicales hacia el sistema de conductos (2).

La existencia en el mercado de varios selladores endodónticos diferentes en composición y marca hacen que el profesional tenga un reto muy difícil al momento de escoger el sellador ideal, sumado a esto no existen suficientes estudios realizados en nuestro medio que manifiesten cual sellador posee mayor actividad antibacteriana, lo que impulsa a investigar sobre la eficacia antibacteriana de distintos tipos de selladores utilizados en la terapia endodóntica contra el Enterococcus faecalis.

El objetivo de este estudio comparativo in vitro, fue comparar el potencial antibacteriano entre tres selladores endodónticos: selladores a base de resina epóxica Topseal (Dentsply/Maillefer-Suiza), a base de hidróxido de calcio Sealapex (Sybron-Kerr), a base de óxido de Zinc y Eugenol Grossfar (Eufar), frente al Enterococcus faecalis.

\section{MATERIAL Y MÉTODOS}

La realización del sembrado y observación de la acción antibacteriana de los cementos selladores endodónticos sobre la cepa Enterococcus faecalis ATCC 29212 se llevó a cabo en el Departamento de Microbiología del Hospital Docente "Vicente Corral Moscoso".

Se tomaron las respectivas medidas de asepsia, antisepsia y bioseguridad; para liofilizar la cepa de Enterococcus faecalis ATCC 29212 (American Type Culture Collection). Para evitar una posible contaminación de la muestra con el medio ambiente, o que esta contamine el mismo, se trabajó en una cámara de Bioseguridad tipo II (BIOBASE), la misma que para ser utilizada debe ser desinfectada previamente du- 
rante 15 minutos mediante luz ultravioleta $(6,7)$.

Después de liofilizar la cepa Enterococcus faecalis ATCC 29212, se procedió a la preparación del inoculo por el método de suspensión directa de colonias, el cual consiste en coger varias colonias con un asa estéril y ajustar el inóculo a una turbidez equivalente al 0.5 de la escala de MacFarland, en suero fisiológico $(7,8)$. Una vez realizado los procedimientos anteriormente descritos, se realizó la inoculación de las placas en el agar de Müller- Hinton, a partir del inoculo se sembró en todo el agar, sin dejar ninguna zona libre. Esto se consiguió deslizando el hisopo por la superficie del agar tres veces, rotando la placa unos $60^{\circ}$ cada vez y pasándola por último por la periferia del agar para conseguir una siembra uniforme (6-8).

Los discos que contenían el sellador fueron elaborados en papel cartulina, debido que este papel resistía a los procedimientos de esterilización. La medida de los discos fue de $6 \mathrm{~mm}$ de diámetro, similares a la que poseen los discos de sensibilidad. Para que los discos que contenían el sellador tuvieran un contacto directo con el agar se los embebió con los selladores por ambas caras, se los colocó en el medio de cultivo con pinzas estériles manualmente y se los presionó ligeramente sobre el medio de cultivo, se los situó a menos de $15 \mathrm{~mm}$ del borde de la placa, y estaban distribuidos de forma que no se produzca superposición de los halos de inhibición; ${ }^{6,8}$ luego se incubó en la estufa a una temperatura de $37^{\circ} \mathrm{C}$ por 24 horas con el objetivo de determinar si existe o no la formación de los halos de inhibición ( figura 1 y figura 2)

Para garantizar la trazabilidad es de suma importancia realizar un control de calidad del estudio para lo que se tomaron algunas medidas (6):

- Los cementos endodónticos fueron preparados según las indicaciones del fabricante, las proporciones para los selladores Topseal y Sealapex fueron 1:1, una porción de base más una de catalizador; para el sellador Grossfar se utilizaron la cuchara y el gotero que viene en el producto las proporciones fueron de una cuchara de polvo y una gota de líquido, posteriormente los selladores fueron mezclados sobre una loseta de vidrio con un porta material, el cual se usó en todos los selladores.

- Se sembró la cepa de Enterococcus faecalis en agar sangre para demostrar que la cepa es capaz de crecer, desarrollarse y multiplicarse formando las respectivas colonias bacterianas.

- De igual manera en cada caja Petri que contenía el agar de Müller- Hinton se colocó las muestras de los selladores en estudio, con dos discos de sensibilidad con antibióticos específicos para el tratamiento de infecciones producidas por Enterococcus faecalis: Sulfametoxazol y el aminoglucósido Amikacina $(6,8)$.

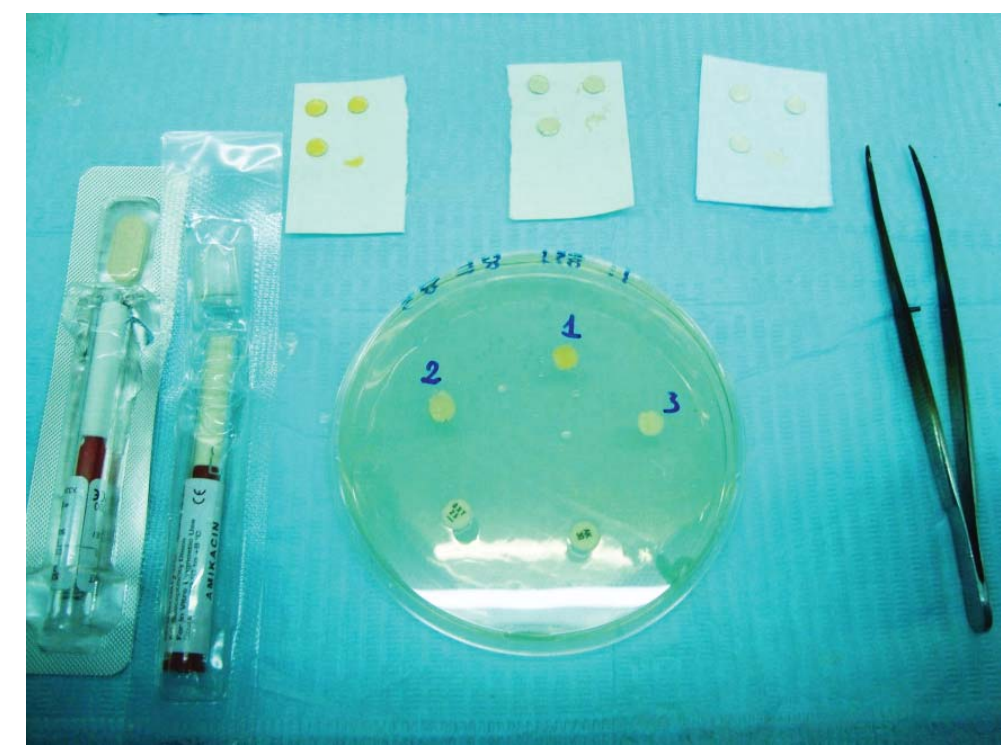

Figura 1. Colocación de selladores y discos de sensibilidad de sulfametoxazol y Amikacina en agar de Müller- Hinton. 


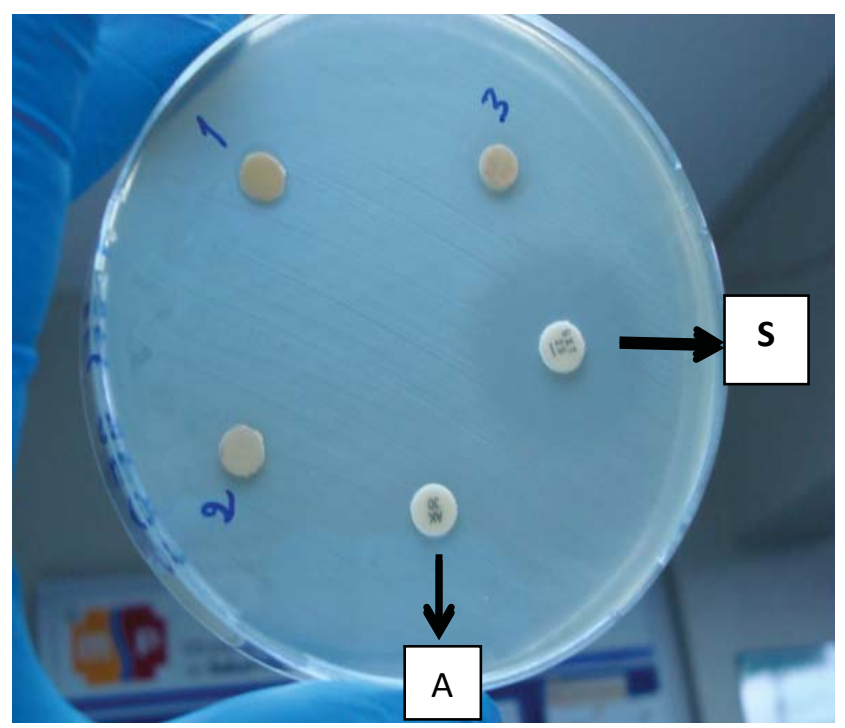

1. Topseal (sellador a base de resina epóxica)

2. Sealapex (sellador a base de hidróxido de calcio)

3. Grossfar (sellador a base de óxido de zinc y Eugenol)

A: Amikacina. S: Sulfametoxazol.

Figura 2. Interpretación de resultados: halos de inhibición formados por los selladores y discos de sensibilidad.

Los análisis estadísticos fueron realizados utilizando el programa SPSS 22.0 (Armont. NY, USA).Los datos obtenidos fueron sometidos al análisis de normalidad de Shapiro-Wilk. Debido a que los datos no demostraron normalidad, las comparaciones fueron realizadas empleando el test de Kruskal-Wallis. Se consideraron resultados significativos niveles iguales o menores al $5 \%(p \leq 0,05)$.

\section{RESULTADOS}

La muestra del estudio estuvo formada por 10 replicaciones experimentales por cada sellador endodóntico, dando un total de 30 unidades de estudio (tabla 1). Según la prueba de Kruskal Wallis $\mathrm{p}<0,001$, los selladores endodónticos utilizados en este estudio no son iguales respecto a su capacidad antibacteriana frente al Enterococcus faecalis (gráfico 1). El sellador a base de resina epóxica Topseal tuvo una media de 7,7 mm y desviación estándar (DE) de 0,67, los valores mínimo y máximo fueron 7 y $9 \mathrm{~mm}$, respectivamente (tabla 2). El sellador endodóntico a base de hidróxido de calcio Sealapex tuvo como media $6 \mathrm{~mm}$ y Desviación Estándar (DE) 0; los valores mínimo y máximo fueron $6 \mathrm{~mm}$ (tabla 3). El sellador a base de óxido de Zinc y Eugenol Grossfar presentó una media de 8,4 mm y una Desviación Estándar (DE) 1,34; los valores mínimo y máximo fueron $7 \mathrm{~mm}$ y $10 \mathrm{~mm}$, respectivamente (tabla 4).

La prueba U de Mann Withney demostró que los selladores endodónticos a base de resina epóxica Topseal y el sellador a base de óxido de Zinc y Eugenol Grossfar no son diferentes respecto a su eficacia antibacteriana. El sellador resinoso Topseal mostró una media de 7,7 mm y una desviación estándar de 0,67; el sellador Grossfar, a base de óxido de zinc y eugenol, mostró una media de $8,4 \mathrm{~mm}$ y una Desviación Estándar (DE) 1,34 con una significancia de 0,315 (tabla 5).

Con respecto a los selladores endodónticos a base de hidróxido de calcio Sealapex y el sellador a base de óxido de Zinc y Eugenol Grossfar, la prueba U de Mann Withney demostró que tienen diferente eficacia antibacteriana. El sellador Sealapex mostró una media de $6 \mathrm{~mm}$ y una desviación estándar de 0 ; el sellador Grossfar, mostró una media de $8,4 \mathrm{~mm}$ y una desviación estándar (DE) 1,34; con una significancia de $\mathrm{p}<0,001$ (tabla 6 ). 


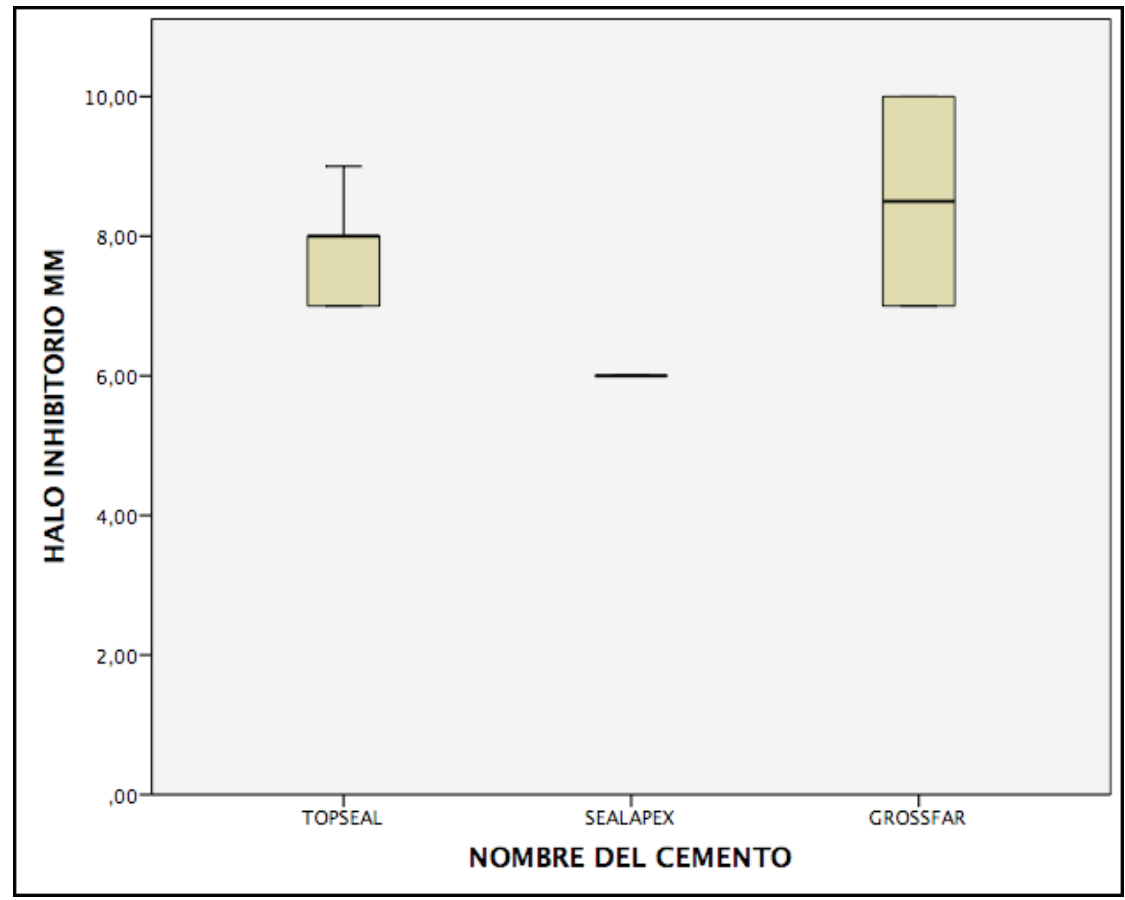

Kruskal Wallis $\mathrm{p}<0.001$.

Gráfico 1. Comparación en los tamaños del halo inhibitorio de tres selladores endodónticos.

Tabla 1. Distribución de la muestra

\begin{tabular}{lll}
\hline SELLADOR & $\mathbf{n}$ & $\mathbf{\%}$ \\
\hline TOPSEAL & 10 & $33,33 \%$ \\
SEALAPEX & 10 & $33,33 \%$ \\
GROSSFAR & 10 & $33,33 \%$ \\
TOTAL & 30 & $99,99 \%$ \\
& \\
\hline n: corresponde al número de discos de sensibilidad utilizados para medir el \\
halo inhibitorio.
\end{tabular}


Tabla 2. Estadística descriptiva del tamaño del halo inhibitorio del sellador endodóntico a base de resina epóxica (Topseal).

\begin{tabular}{|c|c|c|c|}
\hline \multicolumn{3}{|c|}{ NOMBRE DEL CEMENTO } & $\begin{array}{l}\text { I N H I B I T O R I O } \\
\text { mm }\end{array}$ \\
\hline \multirow{8}{*}{ TOPSEAL } & & Válido & 10 \\
\hline & $\mathrm{N}^{\circ}$ & Perdidos & 0 \\
\hline & Media & & 7,7 \\
\hline & Mediana & & 8,0 \\
\hline & Moda & & 8,0 \\
\hline & Desviaci & tándar & 0,67 \\
\hline & Mínimo & & 7,0 \\
\hline & Máximo & & 9,0 \\
\hline
\end{tabular}

Tabla 3. Estadística descriptiva del tamaño del halo inhibitorio del sellador endodóntico a base de Hidróxido de Calcio. (Sealapex)

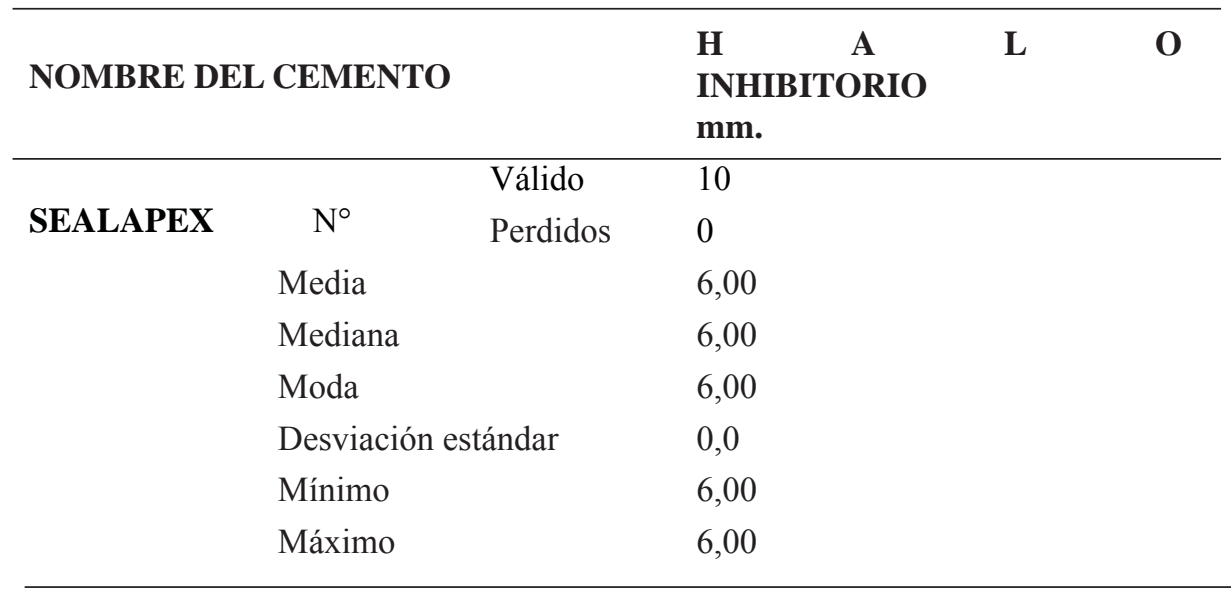

Tabla 4. Estadística descriptiva del tamaño del halo inhibitorio del sellador endodóntico a base de Óxido de Zinc y Eugenol (Grossfar)

\begin{tabular}{|c|c|c|c|}
\hline \multicolumn{3}{|c|}{ NOMBRE DEL CEMENTO } & $\begin{array}{l}\text { H A } \quad \text { L O } \\
\text { INHIBITORIO } \\
\text { mm. }\end{array}$ \\
\hline \multirow{8}{*}{ GROSSFAR } & $\mathrm{N}^{\circ}$ & Válido & 10 \\
\hline & & Perdidos & 0 \\
\hline & $\mathrm{Me}$ & & 8,4 \\
\hline & $\mathrm{Me}$ & & 8,5 \\
\hline & Mo & & 7,0 \\
\hline & Des & tándar & 1,34 \\
\hline & Mír & & 7,00 \\
\hline & Má & & 10,00 \\
\hline
\end{tabular}


Tabla 5. Comparación en los tamaños del halo inhibitorio entre TOPSEAL y GROSSFAR.

\begin{tabular}{cccc}
\hline & MEDIA & DE & SIGNIFICACIA \\
TOPSEAL & 7,7 & 0,67 & $0,315^{*}$ \\
GROSSFAR & 8,4 & 1,34 & \\
\hline
\end{tabular}

* Prueba U de Mann Whitney.

Tabla 6. Comparación en los tamaños del halo inhibitorio entre SEALAPEX y GROSSFAR

\begin{tabular}{lccc}
\hline & MEDIA & DE & SIGNIFICACIA \\
SEALAPEX & 6.0 & 0.00 & $<0.001 *$ \\
GROSSFAR & 8,4 & 1,34 & \\
\hline
\end{tabular}

* Prueba U de Mann Whitney

Tabla 7. Comparación en los tamaños del halo inhibitorio entre TOPSEAL y SEALAPEX.

\begin{tabular}{lccc}
\hline & MEDIA & DE & SIGNIFICACIA \\
TOPSEAL & 7,7 & 0,67 & $<0.001$ \\
SEALAPEX & 6.0 & 0.00 & \\
\hline
\end{tabular}

* Prueba U de Mann Whitney

En cuanto a los cementos selladores endodónticos a base de resina epóxica Topseal y el sellador a base de hidróxido de calcio Sealapex la prueba U de Mann Withney demostró que tienen diferente eficacia antibacteriana. El sellador Topseal mostró una media de 7,7 mm y una desviación estándar (DE) 0,67; el sellador Sealapex, mostró una media de $6 \mathrm{~mm}$ y una desviación estándar (DE) 0; con una significancia de $\mathrm{p}<0,001$ (tabla7).

\section{DISCUSIÓN}

Este estudio demostró la eficacia antibacteriana del sellador endodóntico a base de resina epóxica (Topseal) frente al Enterococcus faecalis después de 24 horas de incubación a $37^{\circ} \mathrm{C}$, mediante el tamaño del halo inhibitorio cuya media fue $7,7 \mathrm{~mm}$, que es un valor pequeño en comparación con los resultados de otros estudios realizados anteriormente como el de
Saha et al. (9), en las que compararon las propiedades antibacterianas de los selladores endodónticos contra siete especies bacterianas, entre ellas el Enterococcus faecalis, en periodos de incubación de 24, 48 y 72 horas así como 7 y 15 días; se encontró 20,33 $\mathrm{mm}$ como promedio del halo inhibitorio del sellador resinoso (AH 26), este halo inhibitorio fue mayor al provocado por el Topseal utilizado en este estudio, debido a la presencia de formaldehido que contiene el sellador endodóntico AH 26, esta sustancia contribuye a la acción antibacteriana ya que es capaz de destruir bacterias, hongos y formas vegetativas $(9,10)$. Sumado a esta última característica el estudio de Saha et al. (9), tuvo mayor tiempo de incubación que el propuesto en esta investigación. Otras investigaciones demostraron valores de la media del halo inhibitorio similares a los encontrados en este estudio; los autores de aquellas investigaciones utilizaron el sellador resinoso AH Plus, que es un sustituto del 
AH 26, basado en un polímero de epoxi amina, que evita la liberación de formaldehído de esta manera se reduce la citotoxicidad, sin embargo las propiedades antimicrobianas también disminuyen (10). El sellador resinoso AH Plus posee una composición similar al sellador a base de resina epóxica Topseal, cemento endodóntico utilizado en esta investigación (11). Maekawa et al., en el 2012, utilizaron el método de difusión en agar Müller- Hinton para comprobar la actividad antimicrobiana de selladores endodónticos frente al Enterococcus faecalis y otras especies bacterianas comunes en las infecciones del sistema del conductos radiculares (12). La media del halo inhibitorio del sellador resinoso AH Plus fue de 7,92 mm que guarda similitud con el halo inhibitorio provocado por Topseal, utilizado en esta investigación.

Leonardo et al., en el año 2000, demostraron la capacidad antimicrobiana de cuatro selladores endodónticos y dos pastas utilizadas en la obturación endodóntica frente a siete especies bacterianas, el resultado del halo inhibitorio en caso de AH Plus fue de 7,7 mm (13), que coincide con el halo inhibitorio formado por Topseal, encontrado en este estudio.

Wainsteim et al., en el año 2016, evaluaron la actividad antimicrobiana, frente al Enterococcus faecalis, in vitro, de dos selladores convencionales, entre estos AH Plus determinando la medida del halo inhibitorio de este sellador con un valor de 9,47 mm (14). Los resultados de los estudios de Wainsteim, descritos anteriormente, mostraron halos de inhibición provocados por AH Plus mayores al encontrado por el sellador Topseal, debido a que en dichos estudios se crearon pozos en la superficie del agar, de esta manera se obtuvo un contacto directo de los selladores y el microorganismo, mientras que en la presente investigación los selladores estaban contenidos en discos de papel cartulina que se pusieron en contacto con el agar sobre el cual se sembró el Enterococcus faecalis. Farmakis et al., en el año de 2012, demostraron la eficacia antibacteriana de Topseal el mismo que provocó un halo de inhibición de $11 \mathrm{~mm}$, Farmakis usó el método de difusión de agar por 24 horas a $37^{\circ} \mathrm{C}$, para ello creó en la superficie del agar un pozo con el fin de tener contacto directo entre el material de estudio y el medio de cultivo, usando una pipeta para un volumen de $0,3 \mathrm{ml}$, los selladores recién mezclados fueron introducidos en el pozo mediante una jeringa de insulina (15). Esta investigación encontró un halo de inhibición provocado por el sellador a base de resina epóxica Topseal de $7,7 \mathrm{~mm}$, el sellador estuvo contenido en un disco de cartulina, el mismo que evitaba un contacto directo entre el material en estudio y el medio de cultivo.

La propiedades antibacterianas de los selladores a base de hidróxido de calcio también han sido investigadas en distintos tipos de estudios por ejemplo Leonardo et al., en el 2000, compararon la actividad antibacteriana de distintos selladores endodónticos frente al Enterococcus faecalis; entre ellos el Sealapex, cemento endodóntico a base de hidróxido de calcio, y dos pastas Calen y Calasept (base de hidróxido de calcio), se utilizó el método de difusión del agar a una incubación a $37^{\circ} \mathrm{C}$ por 24 horas, se elaboraron pozos de $4 \times 4 \mathrm{~mm}$ en el agar, donde los selladores y las pastas fueron colocadas directamente, la medida de los halos de inhibición fue de $13 \mathrm{~mm}$ para el Sealapex; $11,5 \mathrm{~mm}$ para la pasta Calen y $9 \mathrm{~mm}$ para la pasta Calasept (13), estos valores son mayores que los encontrados en este estudio donde la media del halo inhibitorio del sellador Sealapex fue de $6 \mathrm{~mm}$; además de la creación de los pozos en el agar; el estudio realizado por Leonardo incubó por dos horas a temperatura ambiente las cajas Petri después de la colocación de los selladores endodónticos para una difusión del material y posteriormente se los incubó por 24 horas a $37^{\circ} \mathrm{C}$, en esta investigación no se crearon pozos en al agar ya que el sellador estaba embebido en discos de papel cartulina por ambas caras, y no se los dejó a temperatura ambiente ya que fueron puestos en la estufa directamente a una incubación de $37^{\circ} \mathrm{C}$ por 24 horas. Algunas investigaciones como la de Zhag et al., en el 2009, demostraron bajos resultados en la actividad antibacteriana del sellador endodóntico a base de hidróxido de calcio Sealapex, recién mezclado, mientras que al séptimo día todas las muestras mostraron gran actividad antimicrobiana, la posible razón se debe que después de un proceso de polimerización los iones de hidroxilo fueron liberados lo que permitió una actividad antibacteriana (16). A diferencia de lo que sucedió en esta investigación donde la media del halo inhibitorio de sellador a base de hidróxido de calcio fue de $6 \mathrm{~mm}$, ya que la incubación se realizó a una temperatura de $37^{\circ} \mathrm{C}$ por 24 horas.

La literatura cuenta con múltiples estudios que afirman que el sellador a base de óxido de Zinc y Euge- 
nol posee efecto antimicrobiano, el eugenol tiene un efecto bactericida, acción que se ha atribuido a los fenoles por degeneración de las bacterias, hongos y formas vegetativas (10). El presente estudio demostró la eficacia antibacteriana del sellador endodóntico a base de óxido de Zinc y Eugenol (Grossfar) cuyo promedio del halo inhibitorio fue de $8,4 \mathrm{~mm}$; resultados similares a esta investigación se encontraron en otros estudios. Wainstein et al., en el año 2016, demostraron la eficacia antibacteriana del sellador a base de óxido de zinc y eugenol (Endofill) frente al Enterococcus faecalis el cual generó un halo inhibitorio de $8,46 \mathrm{~mm}$, similar al halo inhibitorio formado por Grossfar (sellador a base de OZE) de $8,4 \mathrm{~mm}$, utilizado en esta investigación (14).

Este estudio concluyó que los tres selladores estudiados, no son iguales respecto a su eficacia antibacteriana.

El sellador a base de óxido de Zinc y Eugenol (Grossfar) mostró mayor eficacia antibacteriana contra el Enterococcus faecalis, seguido del sellador a base de resina (Topseal) y el menor efecto antibacteriano correspondió al sellador a base de hidróxido de calcio (Sealapex).

\section{Correspondencia:}

David Heredia Veloz.

Correo electrónico: hdav913@hotmail.com

\section{REFERENCIAS BIBLIOGRÁFICAS}

1. Rodríguez C, Oporto G. Implicancias clínicas de la contaminación microbiana por Enterococcus faecalis en conductos radiculares de dientes desvitalizados: Revisión de la Literatura. Rev Odont Mex. 2015; 19(3):181-186.

2. Cohen S, Hargreaves K.Vias de la Pulpa. Barcelona:Elsevier; 2011.

3. García AG, Garcia AR, Perea Mejia LM. Comparación in vitro de la actividad antimicrobiana de AhPlus, RSA y Ledermix contra Enterococcus faecalis. Rev Odont Mex. 2013; 17(3):156-160.

4. Vanapatla A, Vemisetty H, Punna R, et al. Comparative evaluation of antimicrobial effect of three endodontic sealers with and without antibiotics - An In-vitro Study. JCDR. 2016; 10 (4): 69-72.

5. Balvin W, Castro R. Capacidad antibacteriana de diferentes selladores endodónticos frente al Enterococcus faecalis: Estudio In vitro. Kiru. 2007; 4(1):17-19.

6. Picazo E, editor. Métodos básicos para el estudio de sensibilidad de antimicrobianos. In: Sociedad Española de Enfermedades Infecciosas y Microbiología Clínica. Procedimientos en microbiología clínica. Recomendaciones de la Sociedad Española de Enfermedades Infecciosas y Microbiología Clínica. Madrid: Sociedad Española de Enfermedades Infecciosas y Microbiología Clínica; 2000. p.1-54.

7. Microbiologics. Lab Elite ${ }^{\mathrm{TM}}$ CRM Catalog No. 0367CRM Enterococcus faecalis derived from ATCC $®$ 19433 ${ }^{\text {TM }}$. Minnesota: Microbiologics; 2013.

8. Negroni M. Microbiología Estomatológica: Fundamentos y guía práctica. Buenos Aires: Editorial Medica Panamericana; 2004.

9. Saha S, Samadi F, Jaiswal J N, Ghoshal U. Antimicrobial activity of different endodontic sealers: An in vitro evaluation. J Indian Soc Pedod Prev Dent. 2010; 28: 251-7.

10. Pérez D, Pineda V, Plaza M, et al. Cementos endodónticos. Guatemala: Universidad de San Carlos de Guatemala; 2012. (Citado el 25 de setiembre del 017) Disponible en: https://yazminorozco.files.wordpress. com/2013/02/cementos-endodonticos.pdf

11. Canalda C, Brau E. Endodoncia técnicas clínicas y bases científicas. Madrid: Elsevier Masson; 2006.

12. Maekawa LE, Nassri MG, Ishikawa CK, Martins C, Chung A, Koga-Ito CY. In vitro antimicrobial activity of AH Plus, EndoREZ and Epiphany against microorganisms. Indian J Dent Res. 2012; 23: 469-472.

13. Leonardo MR, da Silva LA, Tanomaru Filho M, Bonifácio $\mathrm{KC}$, Ito IY. In vitro evaluation of antimicrobial activity of sealers and pastes used in endodontic. J Endod. 2000;26(7): 391-4.

14. Wainstein M, Morgental RD, Waltrick SBG, et al. In vitro antibacterial activity of a silicone-based endodontic sealer and two conventional sealers. Braz Oral Res. 2016; 30: 1-5.

15. Farmakis ET, Kontokiatis EG, Tseleni-Kotsoval A, Tsotsa VG. Comparative in vitro antibacterial activity of six root canal sealers against Enterococcus faecalis and Proteus vulgaris. J Investig Clin Dent. 2012; 3(4): 271-275.

16. Zhang H, Shen Y, Ruse N, Haapasalo M. Antibacterial activity of endodontic sealers by modified direct contact test against Enterococcus faecalis. J Endod. 2009;35(7):1051-5. doi: 10.1016/j.joen.2009.04.022.

Recibido: 04-01-2017

Aceptado: 27-05-2017 